\title{
Aspectos sensibles del éxodo venezolano hacia Colombia
}

Sergio Armando Rueda Gómez*

\author{
Reseña de libro \\ Castro Franco, A. (2019). Venezuela migra: aspectos sensibles del éxodo \\ hacia Colombia. Bogotá: Universidad Externado de Colombia.
}

La migración de población venezolana hacia Colombia es uno de los fenómenos demográficos más importantes de la historia reciente. De acuerdo con cifras de Migración Colombia, más de 1 millón de ciudadanos venezolanos se encuentran radicados en Colombia, en una tendencia creciente durante los últimos años. Aunque la situación reporta una máxima atención en materia de política pública, aún existen pocos aportes académicos que permitan entender las diferentes aristas del proceso migratorio y que den luces sobre su adecuado abordaje.

En este contexto, el libro Venezuela migra: aspectos sensibles del éxodo hacia Colombia (Castro Franco, 2019) constituye un importante esfuerzo académico por analizar las principales dinámicas y problemáticas asociadas al proceso de migración reciente de venezolanos hacia Colombia, y es producto de la investigación del equipo del Observatorio de Migraciones Internacionales de la Universidad Externado de Colombia. En tal sentido, constituye una compilación de artículos de diversos autores que, desde ópticas disciplinarias diversas en las ciencias sociales, presentan análisis complementarios acerca del fenómeno migratorio.

En relación con la estructura de los contenidos, el libro hace un abordaje de tres principales aspectos alrededor de la migración. La primera parte analiza, de forma general, el fenómeno migratorio, incluyendo la forma cómo los medios han presentado el tema a

\footnotetext{
* Economista, especialista en políticas públicas y magíster en derechos humanos. Estudiante de la Maestría en Gerencia para el Desarrollo de la Universidad Externado de Colombia. Profesional especializado en políticas públicas del Programa de las Naciones Unidas para el Desarrollo, Bogotá (Colombia). [sergio.rueda01@est.uexternado.edu. co]; [[https://orcid.org/0000-0002-4888-5480]

Para citar esta reseña:

Rueda Gómez, S.A. (2020). Aspectos sensibles del éxodo venezolano hacia Colombia [Reseña: Castro Franco, A. (2019). Venezuela migra: aspectos sensibles del éxodo hacia Colombia. Bogotá: Universidad Externado de Colombia], OASIS, 32, pp. 179-188.

Dor: https://doi.org/10.18601/16577558.n32.11
} 
la opinión pública, el proceso de retorno de colombianos desde Venezuela, la respuesta institucional colombiana en la acogida y la integración de la población migrante en el país.

La segunda parte de esta obra discute acerca de la garantía a los derechos por parte de los migrantes venezolanos en Colombia. Del universo de derechos, se analizan el acceso a los servicios de salud, la inclusión laboral, el respeto al debido proceso en procedimientos de deportación y expulsión, y el acceso a la nacionalidad.

La tercera parte del libro se centra en la población vulnerable venezolana. En tal sentido, este apartado analiza el derecho de asilo de las personas que huyen de la crisis humanitaria de Venezuela, así como una caracterización de población indígena, mujeres y niños, como grupos con mayores condiciones de vulnerabilidad.

\section{ASPECTOS GENERALES DEL PROCESO MIGRATORIO}

En la primera parte de esta obra, que trata sobre aspectos generales del fenómeno de migración desde Venezuela hacia Colombia, se destaca, en primer lugar, que el abordaje mediático de la crisis socioeconómica y política de Venezuela no generó una referencia explícita al fenómeno de migración como tal, sino que se enfocó en un discurso relacionado con aspectos políticos y macroeconómicos de Venezuela, con énfasis particulares en cada año analizado. De este modo, en el período 2005-2012 el énfasis mediático estuvo en el rol del entonces presidente Hugo Chávez y las políticas que se implementaron en su momento, en relación con el Mercosur, el referéndum fallido contra el mandatario venezolano y el despido masivo de trabajadores de la estatal petrolera PDVSA. En el 2013, a su vez, los medios se centraron en el fallecimiento de Hugo Chávez y los acontecimientos políticos posteriores, como la presidencia transitoria de Nicolás Maduro, y su posterior elección en estrecho margen respecto al opositor Henrique Capriles. Al final, respecto a los años 2015 y 2016, si bien se da un viraje hacia la crisis política y económica de Venezuela, solo se abordan los problemas de frontera y la deportación de colombianos, y no hay como tal un análisis del fenómeno migratorio.

Un segundo aspecto a destacar en esta primera sección es el análisis del proceso de retorno de los colombianos que vivían en Venezuela. Respecto al proceso migratorio, se destaca que este ha sido un fenómeno recurrente desde la década de los años setenta del siglo pasado, motivado por la bonanza petrolera en Venezuela, y de forma posterior como consecuencia del conflicto armado interno en Colombia, el cual generó procesos de exilio de víctimas.

En relación con el retorno, se identifican tres grandes hitos: 1) tras el inicio de la era chavista, que supuso el regreso al país de colombianos con cierto nivel de cualificación y recursos; 2) por la intensificación de la crisis humanitaria y el deterioro de las relaciones entre Colombia y Venezuela; y 3) el retorno de población que se encontraba en condición de refugio.

Otro de los aspectos que se analiza es la respuesta institucional para el retorno. Respecto a este tema, se destaca la expedición 
del Conpes 3603 de 2009 y la Ley 1465 de 2012, como marcos normativos. Asimismo, tras el proceso de agudización de la migración en 2015, el gobierno expidió un conjunto de decretos para generar flexibilidad en el acceso a servicios básicos de la población deportada desde Venezuela, pero con alcance temporal limitado.

En toda la descripción del retorno se identifican algunos retos centrales: garantizar condiciones de seguridad para la población víctima que retorna; propender por un proceso de reintegración multidimensional; la migración de larga data y los obstáculos para la integración socioeconómica en Colombia; los retornados recientes por el empeoramiento de las condiciones en Venezuela, con un retorno no preparado y con mayores condiciones de vulnerabilidad; la xenofobia y el papel de la sociedad civil; la dificultad de reintegración económica por subregistro.

Por otra parte, también se analiza la política migratoria en Colombia y sus principales hitos, con un énfasis especial en la introducción de instrumentos recientes producto del fenómeno de migración de población venezolana en el país.

A este respecto, se afirma que el país ha tenido un enfoque de política pública migratoria centrada en la expulsión de connacionales hacia el exterior, como efecto del conflicto armado interno y de la situación socioeconómica nacional, por lo cual las medidas adoptadas se han ubicado en torno a proteger la población migrante colombiana.

El libro señala que solo hasta el 2016, cuando la inmigración de población venezolana era un fenómeno sobre evidente, el
Estado inició cambios en el paradigma de la política migratoria. En tal sentido, si bien las normas de forma estructural siguen siendo las mismas, se han introducido instrumentos de política pública que dan prelación a la atención humanitaria y la protección de derechos de los migrantes extranjeros. De acuerdo con esto, se introdujeron cambios en la resolución de visas, se emitieron las denominadas tarjetas de movilidad fronteriza y los permisos especiales de permanencia, como mecanismos para garantizar una inmigración formal, ordenada y que generara información pertinente para la toma de decisiones. Como aspecto a mejorar, se indica que existen altos costos de transacción que, en algunos casos, generan que la población migrante no pueda acceder a estos mecanismos.

Al cierre de la primera parte del libro, se analiza el fenómeno de integración migratoria de la población venezolana en Colombia, como uno de los principales retos de política pública en la actualidad. En el caso de Colombia y Venezuela, ambos países comparten una historia política común durante la Gran Colombia, y aún hoy hay creencias, cultura, idioma y religión compartidos. Venezuela ha sido históricamente receptor de migración en la región, no solo de países cercanos, sino también de Europa y Asia. Colombia, en contraste, ha tenido un rol distinto por el conflicto armado y la situación socioeconómica del país.

Para este análisis se identifican tres hipótesis en el proceso de integración migratoria: la marginación, cuando se pierde contacto cultural con el país de origen y el de destino; la segregación o separación, cuando se conserva la cultura de origen y se rechaza la de acogida; 
y la asimilación, cuando prevalece el deseo de acoger la cultura de destino.

En el caso de la coyuntura actual, se señala que existe una actitud contradictoria por parte de las comunidades receptoras: por un lado, existe una actitud de solidaridad para ayudar en la crisis humanitaria de la población del vecino país y, por otro lado, existe aversión a la creciente inmigración que, en algunos casos, se asocia con incremento de problemáticas sociales. Los asentamientos humanos de población migrante se incrementan. Ahora bien, el autor destaca que más que un fenómeno anti migratorio o xenofóbico, se está dando la denominada aporofobia, es decir, rechazo a la llegada de población pobre venezolana.

\section{¿SE ESTÁN GARANTIZANDO LOS DERECHOS HUMANOS A LA POBLACIÓN MIGRANTE VENEZOLANA EN COLOMBIA?}

La segunda parte del libro aborda un análisis desde la lógica de los derechos de la población migrante. En términos generales, se puede concluir que no existe una capacidad institucional en Colombia para garantizar los derechos de la población migrante, en el marco de las obligaciones internacionales del Estado, en particular aquellas relativas al Sistema Interamericano de Derechos Humanos.

En tal sentido, en esta segunda parte, donde se analizan los derechos a la salud, el empleo, el acceso a la justicia y el derecho a la nacionalidad, de manera transversal se pueden identificar dos factores asociados: uno, en relación con la situación de origen, donde dichos derechos se encuentran en estado crítico, lo cual justifica en parte el proceso de migración hacia Colombia; y el segundo, respecto a la situación de acogida, donde se evidencia una escasa o nula respuesta para garantizar los derechos vulnerados.

En el caso de la salud, se destaca que la crisis de este derecho en el país vecino ha sido uno de los principales motivos de emigración desde Venezuela. De acuerdo con esto, en el sistema de salud venezolano hay operación intermitente de laboratorios clínicos, desabastecimiento de medicamentos y de otros insumos básicos para la atención de pacientes. Esto ha conllevado al incremento de los casos de enfermedades epidemiológicas, incluyendo aquellas que se consideraban erradicadas como el sarampión y la difteria. Asimismo, respecto a los pacientes con enfermedades crónicas, se resalta que una proporción importante no reciben medicamentos y tratamientos y, por tanto, están en riesgo vital. También existe escasez de métodos anticonceptivos, lo cual incrementa el riesgo de contagio de enfermedades de transmisión y los embarazos no deseados, y se han incrementado los índices de mortalidad materna.

Ahora bien, respecto a la normatividad para el acceso a la salud en Colombia por parte de la población migrante venezolana, se destaca que de acuerdo con la Ley 100 de 1993, por principio de igualdad, este grupo tiene derecho a acceder, siempre que cuente con la documentación que certifique su residencia, incluyendo documentos recién estipulados como el permiso especial de permanencia. De otra parte, se describe que existe una amplia jurisprudencia de la Corte Constitucional que salvaguarda el derecho a la salud de la población migrante venezolana, en términos similares a lo estipulado en las normas vigentes. 
También se han emitido decretos temporales $-1770,1978$ y 1768 de 2015 y 1495 de 2016- para atender la situación humanitaria en materia de salud en las zonas fronterizas, así como otros instrumentos por parte del Ministerio de Salud con propósitos similares.

El libro recomienda, como medidas de política pública en materia de salud, el acceso a documentación para la regularización y el acceso a los servicios de salud de forma más simple y menos costosa que como está estipulado hoy con el permiso especial de permanencia; mayores recursos para la atención de salud de población migrante en municipios donde más se concentra; gestión de apoyo por parte de la cooperación internacional; crear una categoría alterna a los regímenes de afiliación actuales que se financien con esos recursos de cooperación; articulación regional para atender fenómenos epidemiológicos; garantía, sin restricciones, del acceso a la salud para niños, niñas y adolescentes migrantes, y toda población en condición de vulnerabilidad; mejoramiento de las condiciones de vida de la población migrante asentada en el país para evitar propagación de enfermedades; entre otras. En general, se sugiere partir de un enfoque de garantía de derechos y solidaridad por parte del Estado colombiano en esta materia.

El estado del derecho del empleo no es distinto al de salud. De acuerdo con lo estipulado en el libro, en términos de la política de migración laboral de Colombia, se destaca que esta se ha enfocado, principalmente, a la oferta de trabajo, dado que el país fue, durante mucho tiempo, expulsor de población migrante; por tanto, las medidas se enfocaron en la retención del capital humano nacional y en la orientación hacia quienes emigraban.

La política de emigración laboral ha contado con acuerdos bilaterales, con países como España, Canadá y Portugal. Asimismo, y sobre todo a partir de la crisis económica mundial del 2008, se han formulado políticas de retorno laboral, como el plan retorno positivo, la política integral migratoria (Conpes 3603) y la Ley 1465 de 2011, enfocadas en la inclusión laboral y productiva de la población que vuelve al país. Y específicamente, la Ley 1565 de 2012, que estableció las cuatro categorías del retorno: laboral, productivo, humanitario y solidario.

Sin embargo, en relación con la población inmigrante, no ha existido una política pública para su inserción laboral en el país. Tan solo a partir del Plan Nacional de Desarrollo 2010-2014 se presentaron orientaciones sobre migración laboral. Posteriormente, se dio la creación de la Dirección de Movilidad y Formación para el Trabajo y el Grupo de Gestión de la Política de Migración Laboral, en el Ministerio del Trabajo.

En términos propositivos, se rescata la propuesta sobre una política laboral migratoria, la cual, principalmente, incluye una visión de promoción del trabajo decente, un aprovechamiento de la migración laboral en el desarrollo nacional, fortalecimiento de las fuentes de información y de la gobernanza y el acceso, en condiciones de igualdad, a los derechos de la legislación laboral nacional a la población migrante.

Por otra parte, también se propone incluir temas de fortalecimiento de información sobre 
migración laboral, análisis sectorial de vinculación de población migrante, diálogo social para la coordinación de la política migratoria, institucionalización de programas de gestión laboral y un proceso de seguimiento, monitoreo y evaluación. Asimismo, otorga un rol central al Ministerio del Trabajo en toda la propuesta.

Respecto a la migración reciente de población venezolana, en el libro se reseñan los instrumentos coyunturales que han sido establecidos, en relación con las tipologías de visados, el permiso especial de permanencia (PEP) y la ley de retorno, en el caso de quienes también tienen nacionalidad colombiana. Como elemento diferencial, se resalta la expedición de la Circular 0056 de 2017 por parte el Ministerio del Trabajo, la cual habilita a los prestadores del servicio público de empleo para dar orientación a la población migrante en materia ocupacional, lo cual también facilita el proceso de regularización.

A modo de conclusión en términos de empleabilidad para la población migrante, se reitera la importancia de que el país cuente con una política laboral migratoria, la cual, a su vez, se base en fortalecer los sistemas de información; socialización de la información disponible con las entidades competentes en materia migratoria y laboral; un proceso continuo de monitoreo y evaluación en la toma de decisiones; la protección de los derechos laborales de los trabajadores migrantes; y el agrupamiento de la legislación dispersa sobre esta materia.

Por otro lado, el derecho a la justicia para la población migrante también dista de estar efectivamente garantizado. En primer lugar, se hace alusión a la premisa sobre que dicho derecho va más allá de los procedimientos judiciales y, por tanto, aplica para los procedimientos administrativos aplicados al fenómeno migratorio, encabezados en el caso colombiano por Migración Colombia.

En este análisis se toma como referencia las disposiciones del sistema interamericano de derechos humanos y la convención americana, para argüir que el derecho al debido proceso debe incluir, como mínimo, el derecho a la defensa técnica, el derecho efectivo a la asistencia consular, el derecho a no ser privado de la libertad de forma arbitraria, el derecho a recurrir en relación con decisiones que afecten los derechos de los migrantes y el derecho a recibir sentencias motivadas en un tiempo razonable.

$\mathrm{Al}$ analizar los procedimientos administrativos vigentes que permiten la regularización de la población migrante venezolana, se señala que existen restricciones efectivas para garantizar dicha condición y documenta, de forma amplia, mediante citas de notas de prensa, que en Colombia se ha presentado de forma recurrente una vulneración del derecho al debido proceso, de acuerdo con la conceptualización presentada y, en tal sentido, un incumplimiento de la Convención Americana de Derechos Humanos.

Como recomendación en materia de justicia, se afirma que la autoridad migratoria en Colombia debe propender por incorporar en sus decisiones administrativas lo dispuesto por el sistema interamericano respecto al debido proceso y, de este modo, garantizar la protección de los derechos humanos de los migrantes venezolanos.

Finalmente, como parte de este análisis de derechos, se discute sobre el derecho a la 
nacionalidad. En tal sentido, se analiza el acceso a la nacionalidad colombiana, en dos casos particulares: 1) en el caso de los niños de padres venezolanos que nacen en territorio nacional; 2) en el caso de colombianos de segunda generación que nacieron en Venezuela y solicitan, de forma extemporánea, la nacionalidad colombiana.

En el primer caso, se presenta un análisis detallado sobre las disposiciones normativas nacionales en términos de la adquisición de la nacionalidad por parte de extranjeros, en particular, en relación con el nacimiento en territorio colombiano como condición para acceder a dicho derecho. En ese sentido, rescata que Colombia es el único país sudamericano que no reconoce el ius soli (nacionalidad por nacimiento en el territorio del país) absoluto para acceder a la nacionalidad y, por tanto, fija condiciones adicionales, tales como la residencia permanente de los padres. Esta condición, se señala, impide que los venezolanos que cuentan con un permiso especial de permanencia, o quienes se encuentren en una condición irregular en el país, no puedan solicitar la nacionalidad colombiana para sus hijos.

Por otra parte, se analiza la jurisprudencia de la Corte Interamericana de Derechos Humanos alrededor del derecho a la nacionalidad, dentro de lo cual se destaca la obligación de los Estados por evitar la apatridia, incluidas situaciones donde, aun cuando existan mecanismos para que los niños y niñas accedan a la nacionalidad de sus padres, en la práctica resulte imposible como es el caso de la población venezolana, por los altos costos para realizar los trámites respectivos. Asimismo, se resaltan las disposiciones internacionales respecto a los derechos de los niños en esta materia, las cuales coindicen en garantizar la nacionalidad, el nombre y la identidad de los menores como derecho superior.

De acuerdo con lo expuesto, se afirma que en Colombia existe un alto riesgo de llevar a la apatridia a los niños de padres venezolanos que nacen en territorio nacional, por cuatro razones: 1) porque se puede presentar apatridia de facto; 2) porque se exige la tenencia de una visa a los padres para justificar la residencia en el país; 3) porque se niega la posibilidad de acceso a la nacionalidad de los hijos de venezolanos con permiso especial de permanencia; 4) porque las disposiciones de acceso a la nacionalidad van en contravía de los mandatos constitucionales sobre protección de infancia $\mathrm{y}$ adolescencia.

En el caso de la solicitud extemporánea de ciudadanía colombiana por parte de personas que nacieron fuera del país, pero son hijos de padres colombianos, se señala que existen restricciones en los procedimientos formales exigidos por la Registraduría, como contar con copia apostillada del registro civil de nacimiento, el cual es de difícil acceso para la población retornada desde Venezuela. Sin embargo, hay jurisprudencia de la Corte Constitucional que permite flexibilizar los requisitos $y$, por tanto, garantizar el derecho a la nacionalidad en estos casos.

\section{¿Y LOS MÁS VULNERABLES?}

La tercera parte del libro trata aspectos relacionados con población migrante en condición de vulnerabilidad. En síntesis, sobre esta materia se afirma que existen grupos poblacionales 
específicos que tienen mayores riesgos de acceso a los derechos y servicios que les permitan salvaguardar su dignidad humana y, por tanto, requieren una atención diferencial y prioritaria. Se destacan aquí la población en búsqueda de refugio, los niños, niñas y adolescentes, los pueblos indígenas y las mujeres.

En relación con las personas en búsqueda de refugio, se discute acerca de la figura jurídica en el marco de la migración forzada de la población venezolana desde su país hacia Colombia. En tal sentido, se analiza, en un primer momento, el concepto de refugio, desligándolo del asilo, y ubicado históricamente como consecuencia de las graves violaciones a los derechos humanos ocurridas tras la segunda guerra mundial. En tal contexto, surge la Convención sobre el Estatuto de los Refugiados (1951), el Protocolo sobre el Estatuto de los Refugiados (1967) y la Declaración de Cartagena sobre Refugiados (1984), como principales instrumentos internacionales que ampliaron, cada vez más, las condiciones para otorgar el refugio por parte de los Estados.

Es importante resaltar que se reconoce una dicotomía en la figura del refugio, en tanto derecho del migrante que ha sido forzado a salir de su país y, al mismo tiempo, discrecionalidad estatal del país receptor en razón de su soberanía. Esta situación genera que, en muchos casos, el refugio no se conciba como un derecho humano que debe garantizarse y se niegue tal condición por parte de un Estado. En el caso colombiano, el Estado es signatario de los instrumentos internacionales antes mencionados $\mathrm{y}$, adicionalmente, posee disposiciones de derecho interno que son coherentes con los compromisos adquiridos por los convenios suscritos (art. 36 de la Constitución Política y Decreto 2840 de 2013).

No obstante, se afirma que existen obstáculos en Colombia para revisar la garantía del refugio para los migrantes venezolanos. En tal sentido, aunque las solicitudes de refugio han ido en crecimiento en los últimos años, el otorgamiento de esta condición ha sido exigua, lo que a su vez genera una situación de refugiados de facto, esto es, personas que cumplen con las características para el otorgamiento del refugio pero que, administrativamente, no han recibido una respuesta favorable.

Algunos de los problemas que se observan en el país a este respecto tienen que ver con la burocratización de los trámites para solicitar el refugio, porque no se garantiza la reunificación familiar para quienes son solicitantes del refugio sino solo para quienes ya son considerados refugiados, la funcionalidad del salvoconducto otorgado en el proceso de reconocimiento del refugio, la capacidad del migrante forzado para probar su condición e, incluso, el tipo de migración forzada que caracteriza a la salida de venezolanos desde su país que, en algunos casos, no encaja de forma ideal en los conceptos aceptados internacionalmente.

Dos principales conclusiones, entre las muchas presentadas, se derivan del análisis sobre el refugio: la necesaria adecuación institucional del Estado colombiano para lograr que el refugio pueda ampliarse a quienes lo necesitan y, más importante aún, situar en el accionar estatal sobre esta materia la salvaguarda de la dignidad humana de quienes son víctimas de una vulneración sistemática de sus 
derechos, como en el caso del pueblo venezolano, y buscan una protección para sí mismos y sus familias.

Respecto a los pueblos indígenas, como grupos poblacionales vulnerables, se evidencia una vulneración a los derechos de los pueblos yukpa, barí y wayúu, quienes han sufrido fenómenos de desplazamiento en la frontera, condiciones de desnutrición, entre otras afectaciones socioeconómicas. En relación con los niños, niñas y adolescentes, existe un alto riesgo de desescolarización, embarazo a temprana edad, violencia o explotación sexual, consumo de sustancias psicoactivas, entre otros. En el caso de las mujeres, la situación de vulnerabilidad se asocia al riesgo de sufrir trata de personas con fines de explotación sexual; asimismo, la prostitución termina siendo una respuesta a condiciones de precariedad laboral o salarial y, en términos generales, a una necesidad económica de supervivencia en Colombia y para la remisión de dinero hacia las familias en Venezuela.

El libro hace mayor hincapié en el análisis de la vulnerabilidad de las mujeres migrantes venezolanas. En tal sentido, se destaca que las mujeres sufren mayores riesgos en cada etapa de la migración, antes de la partida, al regreso al país de origen, en los países de tránsito y en los países de destino, sobre todo en temas sensibles como la violencia sexual, acceso a empleos precarios, complicaciones en materia de salud sexual y reproductiva, entre otros.

Por otra parte, se indica que, aunque en Colombia existe algún desarrollo normativo para proteger los derechos de las mujeres, incluidas las migrantes, como la Ley 1257 de 2008 (protección contra la violencia y discri- minación hacia las mujeres), la Ley 1719 de 2014 (acceso a la justicia de violencia sexual en el conflicto armado interno) y la Ley 1761 de 2015 (sobre feminicidio), pero indica que estas disposiciones no son del todo efectivas para atender la vulnerabilidad de las mujeres migrantes venezolanas.

En términos generales, las recomendaciones principales versan sobre contar con una política migratoria que incorpore el enfoque diferencial, de modo que la vulnerabilidad sea atendida con acciones afirmativas sostenidas. De igual forma, el Estado colombiano debe brindar asistencia humanitaria y en materia de política pública social, de acuerdo con los compromisos internacionales adquiridos respecto a los derechos humanos de las poblaciones vulnerables analizadas.

\section{REFLEXIONES CRÍTICAS}

Venezuela migra... es, sin duda, una obra pertinente y de alta calidad académica en un momento en que el país requiere insumos para la toma de decisiones en el contexto de la creciente migración de población venezolana hacia Colombia. Antes de la publicación de este libro, aunque pueden identificarse artículos académicos aislados sobre diversos aspectos del proceso migratorio, no se identifica una compilación de carácter integral que analice distintas aristas, y desde distintas visiones disciplinares de las ciencias sociales, como lo hace esta publicación.

Más allá de realizar comentarios específicos sobre cada uno de los capítulos reseñados, vale la pena indicar algunos aspectos que pueden robustecer la investigación académica 
en materia de migración. En primer lugar, desde un punto de vista metodológico y dado el reconocimiento generalizado acerca de la deficiencia de información sobre la migración de la población venezolana y sus efectos, es importante explorar fuentes alternativas de información mediante técnicas de Big Data que permitan ampliar el análisis en cada una de las temáticas abordadas. Así, por ejemplo, la información en redes sociales o la posibilidad de analizar registros administrativos del sector privado (telefonía celular, sector bancario, entre otros), podrían ampliar el espectro de investigación académica. De igual forma, la recopilación de información primaria de tipo cualitativo mediante técnicas que impliquen un contacto directo con la población migrante podría también generar hallazgos complementarios a los ya presentados.

En segundo lugar, en términos temáticos, existen aspectos de alta sensibilidad -a propósito del título del libro- en la migración de venezolanos hacia Colombia que exigen una profundización científica y que, eventualmente, podrían ser un segundo tomo de la obra analizada. En materia laboral, por ejemplo, valdría la pena realizar un análisis sobre el comportamiento del componente salarial en los mercados de trabajo donde participan trabajadores venezolanos, de modo que pueda conocerse si se ha presentado un deterioro relativo de la distribución del ingreso para el factor trabajo en el país.

En términos de la relación entre desarrollo y migración, también está en mora un análisis profundo sobre la contribución de la movilidad masiva de personas y recursos en el desenvolvimiento económico y social de Colombia, un tema que inquieta a todo tipo de actores a nivel nacional. Un tercer tema, asociado al anterior y a algunos de los capítulos incluidos en el libro, se relaciona con el peso fiscal de la migración para el Estado colombiano en temas como salud y educación, y las recomendaciones respectivas en dicha materia. Finalmente, un aspecto que se ha mediatizado con fuerza y sobre el que se exige un abordaje riguroso desde la academia es la seguridad ciudadana, de modo que pueda entenderse a cabalidad dicho fenómeno en clave de emigración. 